\title{
EL ABUSO DEL DERECHO, DEL PODER Y DEL RULE OF LAW
}

\author{
Gianluigi Palombella \\ Universidad de Parma, Italia
}

RESUMEN. Frente a aquellos fenómenos que en nombre de los derechos encubren violaciones a intereses ajenos, el autor italiano propone sustituir la estrategia a la Dworkin que subraya la inviolabilidad e inderogabilidad moral de los derechos sustantivos por un recurso más efectivo para su protección: acudir a las categorías de abuso del Derecho, del poder y del rule of law para desvelar los excesos y mantener las finalidades lícitas para las que fueron concebidos los derechos en cuestión. Después de pasar revista a las corrientes teóricas contemporáneas que atienden a la distinción entre reglas y principios en el Derecho (Alexy, Atienza y Ruiz Manero, Dworkin, Raz), PALOMBella sustenta con dos casos de la Corte Suprema estadounidense la veracidad de sus afirmaciones.

Palabras clave: abuso del Derecho, abuso de poder, Estado de Derecho.

ABSTRACT. Before those phenomena which, in the name of rights, conceal violations of other's interests, the Italian author proposes the substitution of the Dworkin style strategy, which underlines inviolability and moral irrevocability of substantive rights, by a mechanism which protects them more effectively, that is, to make use of the following categories: abuse of a right, of power and of the rule of law, in order to unveil excesses and to fulfil the lawful aims for which the rights in question were conceived. After having examined the contemporary theoretical trends which focus on the distinction between rules and principles in law (Alexy, Atienza and Ruiz Manero, Dworkin, Raz), PALOMBeLLA supports the veracity of his assertions with two U.S Supreme Court cases.

Keywords: abuse of law, abuse of power, rule of law. 


\section{EL LADO OSCURO DEL DERECHO Y LA UTILIDAD DEL CONCEPTO DE ABUSO}

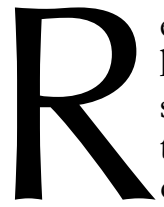

eclamar derechos, principalmente en un intento por garantizar los derechos humanos o derechos fundamentales a escala planetaria, se ha hecho tan persistente que hace temer una inflación universal o una retórica vacía; sobre todo si tenemos en cuenta que la multiplicación de normas que prevén derechos no ha disminuido el riesgo de su violación, si acaso lo ha aumentado ${ }^{1}$. Por otra parte, el impulso dado a los derechos ha asumido casi únicamente formas pretenciosas: en el sentido de que las lógicas de propagación ${ }^{2}$ de los derechos a menudo han revelado raíces individualistas antes que la tendencia intrínseca a hacer justicia en relación con los individuos. Cada vez parece más difícil contener los derechos individuales en un marco coherente, en el horizonte de algún "ordenamiento" jurídico objetivo. Más que una íntima racionalidad universal, la afirmación de los derechos muestra su carácter artificial y político; en realidad, es del todo evidente la imposibilidad de separar la intervención a favor de los derechos de la ponderación de sus "consecuencias", del conocimiento de sus significados y de los contenidos ético-institucionales que adquieren en concreto ${ }^{3}$.

Por otra parte, en muchos ámbitos de los derechos aparece su "dark side"; como en el internacional en los casos del intervencionismo humanitario, o en el de las sociedades democráticas multiculturales, o en el de las democracias en transición; en todos ellos el denial of rights in the name of rights ha visto la luz de muchas maneras, por ejemplo, a través del paternalismo en países como Francia o Turquía donde a las mujeres les está prohibido vestir el bijab en los edificios públicos. Igualmente problemáticas son, por ejemplo, las acciones afirmativas que imponen cuotas reservadas a las mujeres en las listas de candidatos a las elecciones políticas; situación en que la tutela de los derechos políticos sustanciales de algunos se traduce en la negación de los derechos políticos de igualdad de otros ${ }^{4}$.

Además, otro fenómeno que siempre reaparece y que es generalmente descrito como la «negación de los derechos en nombre del rule of law» ha tomado forma específica y adquirido carácter dominante en la experiencia jurídica del "Estado de Derecho" 5 continental europeo. Aquí ha asumido los ropajes de un positivismo legalista, gracias al cual mantiene la defensa del imperativo "dura lex sed lex"; esto, vinculado a una concepción pre-constitucional de la separación de poderes, ha terminado por

\footnotetext{
${ }^{1}$ Pannarale, L., 2001: «Quod alii nocet, et sibi non prosit, non licet», Sociologia del diritto, 2, p. 167.

2 Wellman, C., 1999: The Proliferation of Rights. Moral Progress or Empty Rhetoric?, Oxford: Boulder.

3 Véase Loughlin, M., 2003: The Idea of Public Law, Oxford, pp. 114-130. He tratado extensamente la cuestión en PALOMBELla, G., 2002: L'autorità dei diritti. I dirittifondamentali tra istituzioni e norme, Roma-Bari: Laterza.

${ }^{4}$ Remito aquí al art. 23/2 de la Carta de los derechos fundamentales de la UE: «El principio de igualdad no impide el mantenimiento o la adopción de medidas que ofrezcan ventajas concretas en favor del sexo menos representado».

${ }^{5}$ La expresión se remonta a STAHL, F. J., 1833-7, Philosophie des Rebts, vol. II, 1878: Rechts- und Staatslebre auf der Grundlage christlicher Verfassungsgeschichte, Tuebingen: Mohr. Entre las reconstrucciones italianas del concepto: BaraTTA, A., «Stato di diritto», en NEGRI, A. (ed.), 1980: Scienze politiche, I, Stato e politica, Milano (2. ${ }^{a}$ ed.), pp. 509-523; MargiotTA, C., 2001: «Stato di diritto», Teoria politica, XVII, 2, pp. 17-41. Pietro Costa y Danilo Zolo han recopilado el volumen colectivo: 2002, Stato di diritto, Milano (en particular pueden verse sus ensayos sobre el «Estado de Derecho»).
} 
impedir al orden judicial la defensa por razón de principios de los derechos que no hayan sido regulados directamente por la ley.

En general, frente a fenómenos que en nombre de los derechos o en nombre de los vínculos puestos por el Estado de Derecho encubren violaciones a intereses ajenos, la referencia a la idea de "abuso" puede resultar un buen recurso en la medida en que es un instrumento conceptual muy útil. Y esto debido a que la perspectiva del "abuso" hace emerger la ilicitud de la lesión de un interés por parte del titular de un derecho o de un poder que actúa en aparente conformidad con una regla de Derecho.

Si se supera la ambigüedad de la correspondiente expresión anglosajona abuse of rights, la idea de abuso (que en nuestra lengua tiene sentido en lo posesivo subjetivo ${ }^{6}$ más que en lo posesivo objetivo) * hace evidentes los efectos negativos del "lado oscuro" de los derechos: efectos que se presentan cuando tales derechos son pensados como prerrogativas dotadas de una prioridad tendencialmente absoluta, y amenazan con ser comprendidos (gracias a su carácter deontológico) en sentido moralista, individualista, anti-institucional, etc.

A decir verdad, es muy raro que se recurra al concepto de abuso para defender los derechos. Normalmente, siguiendo una vía opuesta señalada sobre todo por Ronald DWORKIN, más bien se les privilegia, se subraya su inviolabilidad e inderogabilidad; contrario a esta postura, quien acude al concepto de abuso busca los límites al ejercicio concreto de los derechos o poderes lícitos. La estrategia à la Dworkin coincide con la doctrina de los derechos (rights) como derechos "morales" capaces de atravesar las resistencias del Derecho (law) positivo: tal estrategia expresa una concepción "monista" de los principios jurídicos, que los entiende como justificación de derechos individuales y como cartas de triunfo "trump cards" frente a pretensiones opuestas; protege a los derechos como imperativos antes que a los valores, fines o bienes que los derechos aspiran a proteger; de tal modo se les pretende sustraer del riesgo de ser subordinados a social goals o a intereses colectivos ${ }^{7}$.

Con todo, no se ha dicho que esta estrategia sea, en todo caso, vencedora y preferible. Cuando la doctrina de los derechos como trump cards se presenta de forma ideológica amenaza con afirmarse, de igual modo, ideológicamente; ante lo cual se vuelve ciega a los abusos que se pueden cometer en nombre de los derechos, ya sea de parte de sus titulares directos, por parte de los jueces, o por los legisladores.

Además, como Mary Ann GLENDON escribió, «es difícil imaginar en el ámbito europeo contemporáneo a cualquier filósofo del Derecho serio que sustente, como lo ha hecho DwORKIN en Taking Rights Seriously, que "si alguien tiene derecho a algo, es equivocado el negárselo por parte del Estado, aunque hacerlo favoreciera el interés general" ${ }^{8}$. En verdad, debemos reconocer que a veces podríamos tener razones

\footnotetext{
6 Son los propios titulares de los derechos o los poderes los que cometen el abuso. No se trata de un abuso padecido por quien ve violados sus propios derechos, sino de un abuso cometido.

* La referencia es a la lengua italiana (N. de T.).

7 Por ejemplo, Dworkin, R., 1982: I diritti presi sul serio, edición a cargo de ReBuffa, G., trad. de Oriana, F., Bologna, pp. 183-186. Cfr. También en Habermas, J., 1996: Fatti e norme. Contributi a una teoria discorsiva del diritto e della democrazia, edición a cargo de CEPPA, L., Milano, pp. 309 y ss.

${ }^{8}$ Glendon, A. M., 1991: Rights' Talk. The Impoverishment of Political Discourse, New York, p. 40.
} 
para defender, más allá de posiciones como las del "portador solitario de derechos" (lone rights-bearer), una actitud equilibrada basada en el "lenguaje de la responsabilidad", ya sea desde el punto de vista de los particulares o del de las autoridades públicas ${ }^{9}$.

En algunos contextos no podemos evitar que la propia insistencia "política" sobre la solidaridad social pueda ser vista, como ha ocurrido precisamente en los Estados Unidos, como una injustificable limitación de los derechos de libertad o propiedad.

Como quiera que sea, efectivamente, un acento deontológico unilateral sobre los derechos que son "debidos" a cada uno — si se malentendiera- puede generar insensibilidad al problema del abuso de derechos (por parte de su titular).

Es cierto que hay circunstancias históricas y países en los que el problema prioritario es, por el contrario, precisamente la protección y la afirmación de los derechos, países que pudieran padecer retrasos acumulados o la persistencia de una tradición peculiar que, en ocasiones, ha sido definida como "premoderna" ${ }^{10}$. En tales casos, quizás se añora primordialmente una revolución de los derechos, se espera la liberación de los individuos del peso de los vínculos sociales, estatales e institucionales. En estos contextos nuevas constituciones, nuevos órdenes democráticos, garantías del rule of law, o la prioridad de los derechos individuales, hacen presión para instalarse inmediatamente y, al mismo tiempo, sin la larga maduración temporal que uno por uno los ha moldeado y arraigado en otros países de occidente. Pero incluso en tales circunstancias es razonable negarles un tipo de status absoluto, lo mejor es buscar en cada situación razones para establecer relaciones recíprocas equilibradas.

En conjunto, la sensibilidad hacia la paradoja del «rechazo de los derechos en nombre de los derechos o del rule of law» difícilmente puede recibir una respuesta adecuada desde la lógica unilateral, monista, que prevalece en la deontología de los derechos morales; por ello, es preferible recurrir a una tematización del concepto mismo de abuso de los derechos y de abuso del rule of law.

En efecto, la idea de abuso induce a encontrar un límite del cual depende el abuso, un límite que contenga y frene las modalidades del ejercicio concreto de un derecho o del uso de un poder capaces de perjudicar intereses de un tercero, específicamente en aquellos espacios que se presentan como a) prima facie lícitos, b) no atrincherados por otras reglas. Querría que acordáramos aquí que el uso teórico del término abuso se hace en un sentido amplio, en la medida en que se refiere tanto a casos donde alguien ejercita un derecho individual, como a aquellos en los que se ejerce un legítimo poder público, sin ignorar por ello sus profundas diferencias.

En este trabajo comenzaré tratando de indicar algunas características típicas del abuso de derecho; luego ubicaré la relación entre la conformidad prima facie a una regla (lo cual es un presupuesto necesario - aunque no suficiente- del abuso), y un fenómeno distinto cual es el respeto rígido o formalista de las reglas del Estado de

9 Por el contario, los Estados Unidos son definidos como la «tierra de los derechos» (GLENDON, 1991: pp. 1 y ss.); añadiría: más bien la «tierra de los deberes».

${ }_{10}$ Cfr. Sajó, A., Becoming "Europeans": The impact of EU "constitutionalism" on post-communist premodernity, consultable en la dirección electrónica www.iue.it/LAW/Events/WSWorkshopNov2003/Sajo paper.pdf. 
Derecho y del rule of law; después me detendré sobre el caso del abuso de un poder público, igualmente basado en el extrínseco respeto a las reglas legales que atribuyen un poder, indicando al menos algunas características que revelan un particular tipo de abuso generalmente denominado desvío de poder. El abuso de derecho, el abuso de poder público y el abuso del rule of law aparecen como figuras diferenciadas pero unidas por cierto continuo revelador de un uso ilícito e instrumental del Derecho (en sentido objetivo, law). Finalmente, presentaré una lectura resumida de dos sentencias de la Corte Suprema estadounidense que parecen confirmar la utilidad del concepto de abuso de la legalidad y la capacidad del mismo para acercar o reemplazar con éxito en algunos casos las lógicas de la reivindicación de los derechos.

\section{LAS CARACTERÍSTICAS GENERALES DEL ABUSO DE UN DERECHO O DE UN PODER}

En Europa la figura dominante de "abuso" es la del abuso de un derecho subjetivo $^{11}$. El tema del abuso de derecho está referido a la lógica de los derechos subjetivos, como absolutos e inderogables, indica la ruptura de un antiguo paradigma, según el cual qui iure suo utitur neminem ledit, y retoma además la glosa medieval de ACCURSIO (el fragmento D. 39.3.1.12): «item quod alii nocet et sibi no prosit no licet» ${ }^{12}$.

La figura de abuso de derecho a menudo provoca legítimas sospechas porque tiende a condicionar el ejercicio de los derechos ante nociones que pueden llegar a frustrarlos; en el sentido de que a la libertad de fines que debería satisfacer el ejercicio de un derecho se le contrapone el interés social para el cual el derecho ha sido predispuesto, la función que debería desarrollar, el objetivo o las finalidades "típicas" por las que únicamente sería lícito disfrutarlo, entre otras razones similares.

No obstante, se puede convenir que el abuso de derecho puede indicar al menos un principio general de naturaleza jurídica, según el cual «el ordenamiento dispone

\footnotetext{
${ }^{11}$ En algunos ordenamientos está explícitamente prevista. No obstante la fórmula a la que se recurre en Alemania el $₫ 226$ del BGB del 1900, o la prohibición italiana de actos simulados (art. 833 del Código civil), han sido escasamente útiles. El reenvío al Treu und Glauben o el principio de la buena fe (en Italia), han permitido en cambio elaborar y definir casos de abuso de derecho. En todo caso, a título de ejemplo, la Carta de los derechos fundamentales de Niza prevé el abuso del derecho subjetivo en el art. 54. El Código civil portugués del 1996 prevé en el art. 334 explícitamente el abuso de derecho por exceder los límites de la buena fe, de las buenas costumbres o el alejamiento de los objetivos sociales o económicos. En España se ha hecho una codificación expresa sobre el abuso a causa de la reforma al Título Preliminar del Código civil, cuyo art. 7 , más allá de requerir respeto general a la buena fe, declara que la ley no «protege el abuso de derecho o el ejercicio antisocial del mismo». En Francia, en Alemania y en Italia el abuso no cuenta con una previsión explícita y es fruto de la creación jurisprudencial. Tampoco en la doctrina anglosajona hay una adecuada construcción del concepto de abuso o buena fe. Se puede consultar en general a ROTONDI, M. (ed.), 1979: «L'abuso del diritto», Inchieste di diritto comparato, vol. VII, Padova. La reconstrucción de algunos recorridos históricos muy útiles están disponibles en varios volúmenes italianos dedicados al abuso del derecho subjetivo, entre los cuales recuerdo los siguientes: GIORGIANNI, V., 1963: L'abuso del diritto nella teoria della norma giuridica, Milano, pp. 41 y ss.; ResCIGNO, P., 1998: L'abuso del diritto, Bologna, pp. 1965-1966; Levi, G., 1993: L'abuso del diritto, Milano, pp. 25 y ss.; Messina, M., 2003: L'abuso del diritto, Napoli, caps. 2 y 3; GestRI, M., 2003: Abuso del diritto e frode alla legge nell"ordinamento comunitario, Milano, especialmente cap. 1.

${ }^{12}$ Cfr. supra, nota 1.
} 
las normas para su cumplimiento, no para su instrumentalización» ${ }^{13}$. De otro modo, el derecho aparecería como «una pantalla o la cubierta de una conducta arbitraria» ${ }^{14}$.

Pero, como he señalado, el punto de partida es reconocer una peculiaridad del abuso; que tiene que ver con el hecho de que no consiste en la transgresión prima facie de los límites legales fijados por el ejercicio del derecho mismo (en cuyo caso se trataría de exceso y no de abuso), sino que se trata de una «aparente conformidad del comportamiento del sujeto al contenido de su derecho. Por lo que más bien, abusar del derecho debería significar cubrir de apariencia jurídica un acto que se tendría el deber de no realizar» ${ }^{15}$. En efecto, lo que caracteriza el abuso respecto a un simple exceso de los límites legales es la apariencia de legitimidad-legalidad de un comportamiento, lo que permite jurídicamente su tutela ${ }^{16}$. En otras palabras, debe tratarse de una conducta lícita y no de una prohibida directamente o indirectamente por otras reglas. Una de las definiciones más influyentes confirma este punto. La sentencia del Tribunal Supremo español del 14 febrero de 1944 sostiene que «aparte de sus límites legales» hay otros, y luego establece que son «de orden moral, teleológico y social», así que «incurre en responsabilidad el que, obrando al amparo de una legalidad externa y de un aparente ejercicio de su derecho, traspasa, en realidad, los límites impuestos al mismo por la equidad y la buena fe, con daños para terceros o para la sociedad» ${ }^{17}$.

El abuso presupone que a través del uso de un derecho subjetivo reconocido por una norma se provoca un daño a un interés ajeno evidentemente «no protegido por una específica prerrogativa jurídica» (de otro modo nos encontraríamos sencillamente ante un caso de una simple violación de reglas contradictorias, no de un abuso). Según la sentencia española mencionada, el daño debe ser de naturaleza inmoral o antisocial, tiene que ser intencional o bien objetivamente dependiente de un uso excesivo o anormal del derecho. Pero, naturalmente, la fórmula está vacía si no se especifican los criterios que indiquen por lo menos los "síntomas" del abuso. Los "parámetros" a los que ha llegado la jurisprudencia europea en la especificación de una conducta "abusiva" se pueden resumir como sigue: la «falta de interés unida a la intención exclusiva de dañar» (aemulatio), el uso anómalo o incorrecto (por ejemplo la contravención a la buena fe objetiva); la «desproporción inadmisible» de los «intereses perseguidos con respecto de aquellos sacrificados»; la «desviación de poder del objetivo institucional» (detournement du pouvoir) o la combinación de los criterios anteriores ${ }^{18}$. La naturaleza del interés que los derechos protegen, las finalidades por las que se establece un poder o una función pública, el objetivo o la normalidad de su ejercicio deben deducirse de una reflexión ponderada sobre el sistema del Derecho positivo. No pueden ser reducidas a la expresión de un particular prejuicio ético, en cuyo caso se haría del

\footnotetext{
${ }_{13}$ Messina, 2003: p. 181.

${ }^{14}$ BRECCIA, U., 1998: «L'abuso del diritto», Studi in onore di Pietro Rescigno, V, Responsabilità civile e tutela dei diritti, Milano, p. 12.

${ }^{15}$ Natoli, U., 1958: «Note preliminari ad una teoria dell'abuso del diritto nell'ordinamento giuridico italiano», Rivista trimestrale di diritto e procedura civile, p. 37. Naturalmente, la cuestión es localizar de qué deber se trata, y de dónde surge jurídicamente ese deber.

${ }^{16}$ GHestin, Goubeaux, 1990: Traité de droit civil, vol. I, Introduction général, 3. ${ }^{a}$ ed., Paris, pp. 681 y ss.

${ }^{17}$ Véase Dí́z-PiCAzo y Gullón, 1985: Sistema de derecho civil, vol. I, Madrid (5.a ed.), pp. 445 y ss.

${ }_{18}$ Esta síntesis se encuentra en BRECCIA, 1998: p. 24.
} 
titular de un derecho lo que no es: «un guardián del interés del otro o hasta del interés público», ignorando así que los derechos constituyen esencialmente la protección de una ventaja individual: «quien quisiera cambiarla debería luchar por una diferente distribución de los derechos» ${ }^{19}$.

En el plano teórico, más que el señalado por algunas nociones como el interés, el objetivo, o la función, el elemento común a las diversas concepciones del abuso es un ejercicio concreto, generalmente distinto al establecido por los límites sustantivos del derecho o del poder respectivo, límites que son en cierto sentido internos ${ }^{20}$.

La individuación de tal límite de naturaleza "interna" y relativa a su empleo en específico depende en sí mismo de las fuentes positivas. Se ha escrito repetidamente que mientras el exceso de derecho «implica una superación de límites, más o menos generales, pero en todo caso determinados en abstracto y a priori», el abuso de derecho depende de una tipología de normas que permiten una valoración judicial a posteriori. Y en todo caso «siempre queda un juicio de contenido jurídico, cuya aplicación concreta debe desprenderse de las fuentes normativas de rango ordinario y constitucional»; en síntesis, la identificación del abuso depende propiamente del recurso a tipologías de fuentes o normas diferentes ${ }^{21}$, o mejor dicho, pertenecientes a diversos planos.

Para esa finalidad, me parece razonable, desde una perspectiva de teoría del Derecho, especificar en sentido funcional o sistemático qué es lo que ata a una regla a uno o más principios jurídicos en aras de su concreción, es decir, cuál es la llave para remontar aquel empleo ilegítimo del derecho o del poder que constituye un abuso. El abuso de derecho es lo que debería hacer ilícita una conducta que de otro modo sería lícita, son casos en los que la regla por así decirlo parece "supra-inclusiva" ${ }^{22}$. En este sentido, tanto las razones de tal ilicitud, como los criterios para definir cómo algunos casos de ejercicio desvelan a aquellos prima facie permitidos por la regla, es lo que tiene que investigarse bajo o por encima de ella; es decir, en los principios deducibles del ordenamiento: principios relevantes, pertinentes, que ofrecen la o las justificaciones del poder o de la facultad ejercitada, iluminando límites de uso, ya sea en favor del interés privado o del interés colectivo.

\section{REGLAS, PRINCIPIOS Y ABUSO}

Pacíficamente considerados como elementos integrantes de los sistemas jurídicos en nuestras democracias constitucionales, los principios han recibido diversas definiciones respecto de las reglas. Por ejemplo, dentro de su teoría de los "Ilícitos atípi-

19 BRECCIA, 1998: p. 70.

${ }^{20}$ Cfr. BRECCIA, 1998: pp. 71 y ss.

21 Busnelli, F., y Navarretta, E., 1998: «Abuso del diritto e responsabilità civile», Studi in onore di Pietro Rescigno, p. 86.

${ }^{22}$ Atienza, M., y Ruiz Manero, J., 2004: Illeciti atipici, trad. it. de V. Carnevale, Bologna, p. 61, su obra retoma el famoso libro de SCHAUER, F., 1991: Playing by the rules: a philosophical examination of rule-based decision-making in law and in life, Oxford (ed. it. 2000: Le regole del gioco: un'analisi filosofica delle decisioni prese secondo le regole nel diritto e nella vita quotidiana, a cargo de Chiara RUSTICI, Bologna). 
$\cos ^{23}$, ATIENZA y RUIZ MANERO los identifican como elementos que guían la conducta de aquellos que precisamente a través de una ponderación (entre principios) tienen el poder-deber de concretar una norma (judicial, legislativa, administrativa). Otro tipo de principios, los "principios en sentido estricto", incorporan valores últimos que conmesuran sus consecuencias, mientras que en un menor grado de abstracción, las "directrices”, no señalan valores últimos pero también cumplen con la función justificativa de las decisiones. Como quiera que venga propuesta la definición y la función de los principios, en todo caso vale la idea de que ofrecen los criterios a cuyo parámetro es posible acudir para evaluar el abuso de derecho ${ }^{24}$.

En esencia, son los principios los que permiten de entre los posibles supuestos de ejercicio consentidos por la norma (que otorga un derecho subjetivo o confiere un poder o una función) excluir de ella algunos como ilícitos por exceder el ámbito justificado de aplicación de la misma. Esto también vale para casos que atañen a los derechos fundamentales como el ejercicio de las garantías del debido proceso o el derecho de huelga.

Así la tarea del intérprete es especificar qué principios del ordenamiento ofrecen una justificación del poder o del derecho (subjetivo) y en todo caso definir directamente, o por analogía, las relaciones con las áreas de ejercicio que a posteriori se revelen como admisibles o inadmisibles.

Esta cuestión presupone una concepción de los derechos subjetivos basada en una teoría que depende - como Robert AleXY ha insistido- de un papel conjunto de reglas y principios ${ }^{25}$, hasta el punto de que en presencia de casos específicos (donde incluso se cuenta con elementos de hecho para una subsunción ${ }^{26}$ ) también los derechos basados en reglas (definitive rights) tienen que ser ajustados en su alcance concreto por referencia a los principios subyacentes; finalmente también entre estos últimos principios puede ser necesaria una operación de balance y de ponderación ${ }^{27}$. En

23 Atienza, M., y Ruiz Manero, J., 2000: Ilícitos atípicos. Sobre el abuso del derecho, el fraude de ley y la desviación de poder, Madrid: Trotta. Sigo la traducción italiana, AtIEnZa y RuIz MANERO, 2004.

${ }^{24}$ Según AtiEnza y Ruiz MANERO una acción no es abusiva simplemente porque no produzca una mayor utilidad social, en este sentido, contamos con la institución de la «propiedad» por razones "últimas”, por razones de principio, que justifican en los ordenamientos positivos —como el italiano, el francés o el español— el derecho a la propiedad. Ante lo cual, el principio de autonomía no puede justificar por ejemplo un uso anormal que lesione intereses de otros, quedando insensible «al daño causado a intereses ajenos o a intereses colectivos» porque eso a su vez violaría un principio ulterior de igualdad en la protección de la autonomía individual (ATIENZA y RUIZ MANERO, 2004: p. 58).

${ }_{25}$ Para una distinción entre reglas y principios véase, AleXY, R., 1997: Concetto e validità del diritto, trad. de F. FIORE, Torino, p. 73. «Las reglas son normas que, cuando se cumple el tipo de hecho, ordenan una consecuencia jurídica definitiva», por lo tanto son «mandatos definitivos», y la forma de aplicación que les caracteriza es «la subsunción»; en cambio, los principios son «mandatos de optimización» (Optimierungsgebote), como tales «ordenan que algo debe ser realizado en diversos grados» en la mayor medida posible según las posibilidades fácticas y los límites jurídicos que nacen «de los principios contrastantes», esto significa que los principios dependen y requieren ponderación, lo cual es «la forma característica de la aplicación de los principios» (pp. 73-74).

26 ZAgRebelsky, G., quien retoma la teoría de ALEXY, escribe: «Los principios, de cualquier manera, a diferencia de las reglas, son normas sin caso específico (o determinación del hecho "Tatbestand"). En este sentido, los principios no son susceptibles de ser expresados en forma del imperativo hipotético de Kelsen» (Zagrebelsky, G., 2003: «Ronald Dworkin's Principle based Constitutionalism: an Italian Point of View», International Journal of Constitutional Law, vol. I, n. ${ }^{\circ} 4$, p. 630).

${ }^{27}$ Para este tema véase Alexy, R., 2002: A Theory of Constitutional Rights, trad. por J. Rivers, Oxford, pp. 50 y ss. 
efecto, mientras que los principios pueden ser satisfechos "en diversos grados", las reglas, en cambio, gracias a una diferencia cualitativa, «son normas que sencillamente se cumplen o se incumplen» («always either fullfilled or not») ${ }^{28}$.

Esta distinción es parecida a aquella propuesta por Ronald DwORKIN ${ }^{29}$ según la cual las "rules" se aplican "all or notbing", mientras que los principios permiten diversas realizaciones (concreciones), esto es, no exigen una particular decisión. En realidad, según AlEXY, esta distinción todavía puede ser ampliada: también las rules son susceptibles de sufrir una particular excepción y no ser aplicadas en un caso específico, esto precisamente sobre la base de un principio; y este tipo de derogaciones no pueden ser a priori cuantificadas con certeza.

De cuanto he mencionado hasta aquí, se entiende cómo es relevante y determinante la referencia al abuso debido a esa apertura o susceptibilidad de la regla de tener, sobre la base de principios, limitaciones a posteriori.

Como sabemos, no resulta controvertido que, a su vez, también un principio prima facie pueda ser superado por otro de mayor peso en un caso específico. No obstante, una regla no puede ser directa y automáticamente superada por un principio: el principio relevante primero debe ser ponderado con otros que pretenden prevalecer, «como aquel según el cual las reglas emanadas de una autoridad que actúa dentro de sus competencias deben ser obedecidas, o el principio que afirma que no deberíamos distanciarnos de las reglas preestablecidas sin buenas razones. Tales principios pueden ser definidos como "principios formales" ${ }^{30}$.

Los principios formales del tipo señalado por ALEXY a menudo tienden a defender la regla contra su limitación o excepción, y por tanto desempeñan un papel antagónico, son el fondo contra el cual el problema mismo del abuso puede ser contrapuesto. Se ha hecho notar que regímenes no democráticos a menudo han dejado caer en desuso el criterio o la institución jurídica del abuso, evitando con ello que fuera usado en contra del ejercicio de poderes (públicos), exaltando en cambio el formalismo legal: precisamente con el objetivo de impedir el control interno del ejercicio concreto de potestades públicas ${ }^{31}$.

En cierto sentido, la idea de vincular el comportamiento de los individuos y sobre todo el de las autoridades públicas a "normas" (a las puras "reglas") es parte de los

${ }^{28}$ Alexy, 2002: pp. 47-48. Por tanto, según Alexy un regla puede ser «válida o no válida» y en caso de conflicto entre reglas, a menos que una de ellas sea vista como una excepción, al menos una de ellas debe ser declarada inválida. Al contrario, en el caso de principios en conflicto, uno debe prevalecer, mas esto no significa que en alguno de ellos se contenga una excepción ni que alguno sea inválido (ALEXY, 2002: p. 50). Consecuentemente, «conflictos entre reglas ocurren en el nivel de la validez, puesto que sólo los principios válidos pueden entrar en competición, en cambio la competencia entre principios ocurre en la dimensión del peso» (ibid.).

${ }^{29}$ Dworkin, R., 1982: pp. 90 y ss.; Alexy, 2002: p. 48, nota 27.

${ }^{30}$ Alexy, 2002: p. 58.

${ }^{31}$ Según algunos en la España franquista el recurso al formalismo fue el modo de sustraer la discrecionalidad de los poderes administrativos a algún tipo de control, situación que sería dejada de lado con la Constitución española de 1978, al surgir la institución del desvío de poder (ATIENZA y Ruiz MANERO, 2004: p. 100). A propósito de esta cuestión agradezco a Luis María Díez PICAZo por sus comentarios, especialmente por su crítica, por otra parte fundada, sobre la conexión unívoca entre el formalismo y los regímenes totalitarios. 
requisitos esenciales del Estado de Derecho ${ }^{32}$; pero siempre y cuando se piense en el principio de legalidad del Estado de Derecho decimonónico de la Europa continental, y en la definición weberiana del Estado de Derecho como poder legal-racional ${ }^{33}$. El respeto a las "reglas" permite al rule of law, entendido en sentido teorético no histórico, asumir las funciones y el significado que ha asumido. Ello gira en torno a criterios atribuibles a principios "formales", tal y como se deduce de la enumeración provista por autores como Lon FULLER: generalidad de la ley, promulgación, irretroactividad, claridad de las normas, no contradicción, posibilidad de su cumplimiento (la no imposibilidad), adecuación en el tiempo y otros que se desprenden de los mismos ${ }^{34}$.

FULLER especificó en esta aportación muy general los principios de irretroactividad, publicidad y los demás mencionados, también la prueba de una moralidad intrínseca (inner morality). La discusión sobre la importancia de los así llamados vínculos formales del rule of law, de sus requirements periódicamente regresa sobre las controvertidas hipótesis del significado moral del Derecho en la civilización occidental ${ }^{35}$. La importancia de limitar la discrecionalidad del intérprete, de asegurar previsibilidad, coherencia, certeza y conocimiento a los ciudadanos, de excluir las condiciones para la arbitrariedad del poder es universalmente reconocida y confiada a aquellos requisitos insustituibles; pero todo esto sólo es válido si como consecuencia se atribuye al rule of law (como anoté en el caso de FULLER) una "inner morality" ${ }^{36}$; aunque esta moralidad intrínseca esté negada y considerada más bien externa al Derecho ${ }^{37}$.

Naturalmente, en el caso del abuso también debe ser concebible la superación de aquellos principios formales; por tanto, una derogación en este ámbito tiene que ser

${ }^{32}$ Naturalmente, la definición de Rule of Law ofrecida por Albert Venn DiCEY en Gran Bretaña es diferente y más compleja; hace referencia a una visión histórica particular: para DicEY el rule of law incorpora la garantía de las libertades individuales, la no arbitrariedad del poder, y la igual sumisión de los poderes públicos y los ciudadanos particulares al common law (cfr. DiCEY, A. V., 1885, 1956: An Introduction to the Study of the Law of the Constitution, ed. por Londres: E. C. S. Wade, pp. 183 y ss; p. 188; p. 193).

${ }^{33}$ La subordinación del Estado a la ley y a los otros dogmas del Derecho público europeo continental se encuentran en el formalismo de Paul LABAND, 1867-82: Das Staatsrecht des Deutschen Reiches, en GERBER, C. F., 1971: Diritto pubblico, trad. it. de LuCCHINI, P. L., Milano; y otros juristas contemporáneos. Acerca del estado de la justicia administrativa, $c f r$. Nigro, M., 1987: Giustizia amministrativa, Boloña, p. 33. WeBER, M., 1961 (Economia e Società, a cargo de Rossi, P, vol. II, Milano, pp. 16 y ss., pp. 110 y ss.), identificó el carácter "formal" del Derecho en el Estado moderno y, por el contrario, entendió la "racionalidad material" del Derecho como la que toma en consideración normas derivadas de objetivos éticos o conexos a objetivos utilitarios, antes que a normas jurídicas. La crítica más corrosiva del principio de legalidad del Estado de Derecho se remonta a SСHмiтT, C., 1993: Legalität und legitimität, Berlín.

${ }^{34}$ Fuller, L., 1986: La moralità del diritto, a cargo de Dal BROLLO, A., Milano, pp. 65 y ss. Existen otras versiones como la presentada por Joseph RAZ, 1977, 1979: «The Rule of Law and Its Virtue», The Authority of Law, Oxford, pp. 210-229; o el trabajo de Andrei MARMOR, 2004: «The Rule of Law and Its Limits», Law and Philosophy, 23, pp. 1-43. Todos se refieren a las características del Derecho en cuanto tal.

35 Recientemente se puede ver la discusión entre Kramer y SimmONDS: KrameR, M. H., 2004: «On the Moral Status of the Rule of Law», The Cambridge Law Journal, 63, March, pp. 65-97; SimmOnDS, N. E., «Straightforwardly False: The Collapse of Kramer's Positivism», ibid., pp. 98-131.

${ }^{36}$ Más allá de Lon FulLER son dignas de mencionar las críticas lanzadas por J. HABERMAS respecto a la "indiferencia" moral atribuida por Max WEBER al Estado de derecho. Cfr. HABERMAS, J., 1992: Morale diritto politica, a cargo de CEPPA, L., Torino, pp. 5-80 (se trata de la edición italiana de 1988: Recht und Moral, Tanner Lectures on Human Values, Salt Lake City, vol. VIII, pp. 217-279).

${ }^{37}$ Como ha sostenido HarT, H. L. A., 1965: «The Morality of Law - by L. Fuller», in Harvard Law Review, n. ${ }^{\circ} 78$, pp. 1281-1296. 
entendida en el sentido de una reducción del área autorizada por la regla; con lo cual no nos encontramos frente a una excepción determinada por el recurso a la equidad o a la justicia del caso particular. De esta forma, el abuso no constituye una derogación basada en la singularidad del caso particular ${ }^{38}$, sino que depende, a su vez, de una regla general basada en principios de carácter también general y producida a causa del descubrimiento, a posteriori, de la ilicitud de una conducta que en abstracto y $a$ priori era lícita.

Podemos sostener que la resistencia de las rules a la penetración de los principios, o sea, a la admisibilidad de una regla ulterior que constituya la concreción de un principio concurrente, sólo se garantiza gracias al peso de otros principios de naturaleza formal (reconducibles a los de regularidad, publicidad y generalidad) ${ }^{39}$; tales principios son ciertamente el patrimonio civilizatorio normalmente acreditado al rule of law entendido como concepto teórico general; al que, sin embargo, confiamos la específica capacidad de resistencia del Derecho a las exigencias externas, la definición de sus confines, y en un cierto sentido su propia "autoridad".

\section{PRINCIPIOS Y ABUSO DEL RULE OF LAW}

Como se verá, utilizar la resistencia de los principios formales como escudo tras el cual esconder objetivos incompatibles con el ordenamiento jurídico, ciertamente podría configurarse, por usar una expresión sintética, como un abuso del rule of law.

Ello independientemente del hecho de que se consideren cuando menos al rule of law y a sus requisitos como dotados de una virtud "moral" o de algunas específicas cualidades éticas. Sobre este punto volveré dentro de poco; aunque en realidad para los objetivos de comprensión del "abuso" no hace falta solucionar el dilema de la naturaleza de las virtudes propias del rule of law.

El punto fundamental para nuestra discusión es que la derogación o la aplicación de una regla no puede depender de efectuar una comparación directa entre la regla y el principio sustantivo que debería ceder (la libertad de expresión, el derecho a la salud, la igualdad, etc.). Sólo se puede permitir una limitación al ámbito (lícito) determinado por una regla después de una ponderación que sobrevenga pero entre entidades ubicadas en el mismo plano, por tanto, entre principios: el principio sustantivo relevante y los principios formales que exigen un riguroso respeto del carácter definitivo asumido por las reglas.

En un célebre manifiesto sobre las convicciones que sigue como juez de la Corte Suprema estadounidense, Antonin SCALIA ha puesto en primer orden la dicotomía entre el respeto al rule of law general (como "derecho de las reglas", law of rules) y los efectos de la renuncia a este parámetro que se pueden resumir en la discreciona-

38 En el sentido del recurso a la equidad o a la no aplicación de la regla, señalado por BLACKSTONE, W., 1978: Commentaries on the laws of England, vol. 1, New York (Garland) (reimpresión de la edición por STRAHAN, A., y CADELL, T., 1783: Londres), pp. 59-62.

39 Aquí retomo una versión de estos principios ofrecida esta vez por Lawrence SoLUM, quien los resume para hacer evidente el contraste con la "equidad", 1994: «Equity and the Rule of Law», en The Rule of Law, Nomos XXXVI, New York: ed. de J. ShaPIRO, p. 129. 
lidad de la justicia de las Cortes ${ }^{40}$ que, en consecuencia, estaría autorizada. SCALIA sostiene que las Cortes deberían decidir tratando de definir reglas generales para los casos particulares, sobre todo por razones que residen en el respeto al principio del igualdad de trato y de previsibilidad (predictability) («there times when even a bad rule is better than no rule at all») ${ }^{41}$. SCALIA se refiere a la aproximación que la Corte debería elegir: si decidir basándose «en el conjunto de las circunstancias de hecho» que caracterizan el caso particular, o determinar una regla que pueda valer por la mayoría de los casos. En su opinión, el punto relevante está en que el rule of law exige al juez que recurra a reglas generales, antes que a formular decisiones cuyas "razones" valgan sólo para el caso particular.

Desde luego, esta posición en sí misma no es de ninguna manera inaceptable. No obstante, sobre la base de esta construcción, el respeto (de los principios) del rule of law puede volvernos del todo insensibles a los casos de abuso de derecho.

Es verdad que la definición de ilicitud de un acto puede ser conforme con una regla y, no obstante, ser contrario a las razones conexas de un principio, situación que puede desembocar en la definición judicial de una nueva regla que valdría para la mayoría de casos análogos. También es verdad que la fidelidad a la idea de rule of law como law of rules, como Derecho de las "reglas", que se encomienda a ellas como valor último siempre jerárquicamente prioritario, es inaceptable en el ámbito constitucional. Los Estados constitucionales muestran reticencia a proclamar y considerar sólo a algunos de sus principios como absolutos ${ }^{42}$, incluso aquellos "formales", saben que no pueden evitar el criterio de proporcionalidad, el cual debe considerarse fundamental en las operaciones de ponderación ${ }^{43}$. Una visión "absolutista" del rule of law como law of rules violaría el estatuto general de los principios en el Estado constitucional; estatuto esencial e inderogable para conservar la identidad de un determinado ordenamiento jurídico, el cual representa los esfuerzos ético-políticos expresados en standards irreducibles a los "principios formales".

En términos generales, la perspectiva del abuso de poder o de derecho señala que no se puede obedecer sólo al formalismo del rule of law; no porque ello impida la justicia en el caso particular, sino porque ese formalismo haría imposible someter a algún tipo de control el poder que el abuso "legalista" puede ocultar.

El peligro es pues desactivar la normativa de los principios sustantivos que constituyen la identidad ético-política de un específico sistema jurídico constitucional. Los principios sustantivos merecen una consideración que no puede ser clausurada a priori, justamente porque es impuesta jurídicamente dentro de un ordenamiento.

Por último, para la comprensión del concepto de abuso se debe tener en cuenta el hecho de que tanto la teoría como la experiencia de los órdenes euro-continentales no inducen a relacionar a los "principios" exclusivamente con la tutela de derechos individuales, como por el contrario sostendría Ronald DwORKIN, sino que el área

${ }^{40}$ Es decir, the personal discretion to do justice (SCALIA, A., 1989: «The Rule of Law as a Law of Rules», University of Chicago Law Review, 56, p. 1176).

${ }^{41}$ SCALIA, 1989: p. 1179.

42 Zagrebelsky, G., 1992: Il diritto mite, Torino, cap. VI.

${ }^{43}$ Cfr. Alexy, 2002: pp. 66-69 y 397-414. 
semántica de los principios también se extiende a razones que tienen que ver con la protección de intereses colectivos, y por lo tanto de intereses públicos ${ }^{44}$.

Para encuadrar la compleja competencia entre las diversas tipologías de principios es esencial considerar que ello sólo es posible a partir de la comprensión de fondo de los vínculos del rule of law y del Estado de Derecho; razón por la cual resulta significativo el balance ofrecido hace algunos años por Joseph RAZ sobre el sentido del rule of law del que desprende una concepción neutral. RAZ se concentra en el "sentido literal del rule of law" ${ }^{45}$, desde donde deduce que el rule of law puede mostrarse compatible también con «profundas violaciones de los derechos humanos» ${ }^{46}$. Afirma que respetar el rule of law no garantiza que no ocurran violaciones a la dignidad humana. Pero «está claro que el deliberado desprecio del rule of law viola la dignidad humana» por el hecho de que conduce a la «incertidumbre» y a la frustración de «expectativas» (expectations) ${ }^{47}$.

De estas consideraciones no sigue RAZ que los sistemas jurídicos no contengan al menos algún tipo de valor moral. El rule of law tiene —afirma RAz - un «valor negativo»: el Derecho inevitablemente limita la autonomía de los individuos, en consecuencia crea el peligro de un poder arbitrario, por tanto el rule of law está llamado a prevenir el peligro creado por el propio Derecho ${ }^{48}$. Esto, sin embargo, es sólo el Dere-

${ }^{44}$ Muchos juristas en Europa y en Italia dotados de un agudo sentido de conciencia "social" concuerdan con la visión deontológica dworkiniana de los derechos individuales porque en realidad pasan por alto sus verdaderas consecuencias teóricas. La idea de los derechos es la base para sostener argumentos a favor de la autonomía individual y en contra de las elecciones colectivas, y por tanto en contra de la autonomía pública; constituye la manera de contrastar la nivelación redistributiva, igualitaria, que DwORKIN supone implícita en la lógica de la deliberación política y legislativa además del modo para reducir, y limitar, el paternalismo que él cree resulta de las decisiones colectivas en cuanto tales. He tratado este punto en 2002: L'autorità dei diritti, Roma-Bari, p. 53. Las preferencias colectivas son inevitablemente "externas"; en otras palabras, ellas se ocupan de lo que otros deberían hacer o tener (Cfr. DwORKIN, 1982: pp. 328 y ss.). Una crítica explícita de la ecuación principios-derechos individuales está en AlEXY, 1982: pp. 65-66; y ahora también en ZAGREBELSKY, 2003: pp. 642-643.

${ }_{45}$ RAZ, J., 1979: «The Rule of Law and Its Virtue», The Authority of Law, Oxford: Clarendon Press, p. 213. RAZ enumera ocho requisitos que considera incluidos por definición en el concepto y que se desprenden de dos aspectos fundamentales según los cuales los ciudadanos, a) deben guiar su comportamiento por el Derecho y deben obedecerlo; y $b$ ) el Derecho debe ser susceptible de ser obedecido. Los principios son enumerados en las pp. 214 a 219. Entre ellos, se subraya el requisito de que legislación y las decisiones sean «guided by open, stable, clear, and general rules» (p. 215); tal requisito parece corresponder con aquel preferentemente valorado por el juez de la Corte Suprema americana Antonin SCALIA, 1989. Otro requisito, el quinto «the principles of natural justice must be observed», p. 217, merece especial atención; RAz habla de «[O]pen and fair hearing, absence of bias, and the like», lo cual considera esencial para la correcta "aplicación" del Derecho y para su capacidad de guiar las conductas ( «are obviously essential for the correct application of the law and thus, through the very same considerations mentioned above, to its ability to guide action»). El mismo criterio, la capacidad de guiar la acción, es una de las razones para la independencia del orden judicial (que hace posible «to apply the law correctly») (RAz, 1979: pp. 216-217). Como se puede comprender aquí ya estamos en la organización de los poderes; la separación e independencia de los poderes aparecen como un vínculo particularmente unido al Estado moderno en sus estructuras liberales. Sin embargo, no asumen tal ropaje en RAZ, para el que son un requisito funcional conexo a la prestación "neutral" de guiar eficazmente las conductas.

${ }^{46}$ Ello no asegura a los individuos de la «governmental interference» (por lo demás, el derecho podría «instituir la esclavitud sin violar el rule of law»). No obstante, el rule of law contribuye a asegurar el respeto a la dignidad humana, es decir, a la "autonomía" de los seres humanos entendidos como «persons capable of planning and plotting their future» («their right to control their future») (RAz, 1979: p. 221).

47 RAZ, 1979: pp. 221 y 222.

48 «The rule of law is a way to avoid the danger caused by the law itself» (RAZ, 1979: p. 224). 
cho en su propia y específica excellence, no una virtud moral, aunque sí que constituye «la condición necesaria para que el Derecho sirva directamente a cualquier buen propósito en absoluto» ${ }^{49}$. La neutralidad del rule of law hacia los fines es en sí la virtud del Derecho, mas no tiene ningún valor moral. Finalmente, prosigue RAz, se debe rechazar la idea de Friederick HAYEK según la cual el rule of law representa al supremo garante de la libertad; esta convicción nos situaría sobre una pendiente resbaladiza que conduce inexorablemente a la identificación del rule of law con el «rule of the good law» ${ }^{50}$. Por tanto - según RAZ-, desde el momento en que el rule of law es un instrumento, no puede también constituir un fin último: cuando nuestras metas son incompatibles con el rule of law, quiere decir que no pueden ser perseguidas por medios jurídicos; por último, advierte que «debemos de ser cautos al descalificar la persecución jurídica de grandes metas sociales en nombre del rule of law», porque, después de todo, el rule of law está hecho para ayudarnos a sustentar y promover de la mejor manera precisamente aquellos fines comunes: «sacrificarlos sobre el altar del rule of law volvería al Derecho inútil y vacío» ${ }^{51}$.

Ahora bien, no creo que necesariamente se tenga que asumir la complejidad de la teoría general de RAZ y su “positivismo exclusivo”; más aún que me siento inclinado a considerar plausible un "positivismo inclusivo", el cual acepta en la regla de reconocimiento que la norma fundamental de un ordenamiento "pueda" incluir criterios o principios sustantivos ${ }^{52}$. No obstante ello, la tesis de RAZ acerca del rule of law provee un punto de vista óptimo para rechazar dos "fundamentalismos" opuestos: por un lado, aquel que identifica al rule of law como ideal último, y por otro, aquel extrapositivista que lo entiende como set de principios sustanciales, en particular unidos al valor último de los derechos individuales. Si se admite que el rule of law constituye, al menos para ciertas posturas, un instrumento que nos permite perseguir diversos fines, entonces no podemos más que respetar sus requisitos, sus vínculos, que al mismo tiempo no deben ser transformados de medios a fines.

Resulta oportuno subrayar que esta definición del rule of law como "instrumento" debe ser mitigada y comprendida en profundidad. En el fondo, los requisitos "fullerianos" del rule of law son también para RAZ una propuesta, una premisa que puede ser negativa en relación con el respeto de la dignidad de los individuos ${ }^{53}$. Esta consi-

\footnotetext{
49 RAZ, 1979: p. 225.

50 RAZ, 1979: p. 227.

51 RAZ, 1979: p. 229: «Sacrificing too many social goals on the altar of the rule of law may make the law barren and empty».

52 He tratado el tema extensamente en Palombella, 2002. Sobre el tema se pueden ver dos trabajos recientes, Giordano, V., 2004: Il positivismo e la sfida dei principi, Napoli, y BongIOvanni, G., 2005: Costituzionalismo e teorie del diritto, Roma-Bari, pp. 59-150.

53 Como lo he mencionado antes (RAZ, 1979: p. 222), esta relación necesaria es muy significativa, mas no puede ser discutida aquí con la amplitud suficiente, más allá de la compatibilidad entre la "neutralidad" del rule of law y la "dignidad". Se debe recordar que FULLER ha tocado un punto parecido llegando a conclusiones diferentes: él señala que aunque quede claro que la observancia de la «moralidad jurídica» pueda «servir a los objetivos más variados», y que la «moral jurídica puede decirse neutral acerca de una variada serie de cuestiones éticas», en cualquier caso no puede ser neutral acerca de la concepción del hombre mismo. Emprender la empresa de someter la conducta humana al gobierno de normas, implica necesariamente la adhesión a la visión según la cual el hombre es, o puede volverse, un agente responsable, capaz de comprender y seguir normas, y de contestar sus faltas». Así, «Cualquier alejamiento de los principios de la moral interna del Derecho es una afrenta a la dignidad del hombre como agente responsable» (FuLLER, L., 1986: pp. 210-211). Esta
} 
deración abre un espacio controvertido y espinoso, ya que es una manera de hacer emerger el hecho de que el Derecho entendido según el rule of law es portador de pretensiones "negativas" de "justicia" que tienen su propio "peso".

RAZ no parece profundizar en todas las implicaciones de este filón. Su definición del rule of law como "medio" se refiere - al menos en las intenciones- a cualquier tipo de Derecho, y está ligada a la convicción de que la prestación esencial del Derecho como tal es ejercer autoridad sobre las conductas. Bajo esta perspectiva, la definición no protegería ni perjudicaría formas ulteriores, esto es, "los objetivos sustantivos" que históricamente ha asumido el Derecho. Por otro lado, a mi modo de ver, tampoco coincide con el Derecho moderno en la definición kantiana; la cual incluye en sí misma la conexión esencial entre justicia formal y Derecho. El Derecho moderno en la versión de KANT parece haber superado la simple cuestión de la función o de un Derecho cualquiera - a menos que la idea misma de "justicia formal" sea vaciada de todo contenido.

En opinión de KANT, el Derecho entendido como el conjunto de las condiciones de coexistencia de las libertades podría parecer marcado por un objetivo principal: el de una sociedad liberal de mercado. En realidad, quizás a diferencia de la definición de HAYEK (criticada por RAZ por el incorrecto paso del rule of law al rule of the good law), la definición kantiana no queriendo contener nada «tomado de la ética» apunta sólo a señalar las condiciones racionales de justicia intersubjetiva, defendiendo la independencia de los individuos y su autonomía privada en su esfera externa de la coexistencia. Pero, justamente, el rule of law, siguiendo con RAz, contiene menos de aquello que KANT asume como propiedad racional del Derecho moderno; aparece como un concepto "técnico" acerca de las propiedades necesarias para que el "Derecho" logre guiar las conductas de manera eficiente, mientras que la definición kantiana se refiere a un ordenamiento en cuyo seno quedan garantizadas las dignidades separadas de las esferas individuales. KANT no parte, como RAZ, del presupuesto de que el Derecho atañe al problema del ejercicio de una autoridad eficiente sobre los individuos,

controvertida relación "neutralidad"-"dignidad" es un punto que no se debe subestimar. A su modo, moralidad del Derecho y ética u objetivos sustanciales son para FULLER dos conceptos separables; aunque sólo hasta cierto punto: la compatibilidad entre moral del Derecho y sus posibles objetivos sustantivos no puede extenderse a aquellos objetivos sustanciales que contradigan la dignidad de los hombres como agentes responsables ( $y$ por tanto al presupuesto ético que los une). Como he recordado otras veces, personalmente prefiero considerar las lógicas estructurales del Derecho como una cuestión de justicia, de no confundirlas con los objetivos éticos de los ordenamientos; la justicia indicada por KANT, entendida como la definición de las condiciones de coexistencia. No creo que las instituciones clásicas y los principios funcionales del Derecho moderno sean un simple medio técnico para guiar las conductas, es evidente que contienen condiciones de justicia para las relaciones intersubjetivas, y confían al Derecho un papel de «equilibrador» de «contenidos» o de objetivos externos. No obstante, resulta evidente que los objetivos éticos de un ordenamiento son conceptualmente otra cosa y son ampliamente incensurables. Ampliamente, pero no totalmente. FulLER tiene razón al creer que si la dignidad sólo se puede tutelar a través de los cánones del rule of law, entonces este último es compatible para cada sociedad que persiga cualquier idea del bien, pero no para aquellas que mancillan la idea de "dignidad". El problema se puede explicar recurriendo a KANT, o por lo menos a la interpretación que considera KANT en la que distingue entre la tutela de la autonomía de cada uno, como facultad de elegir, y la tutela de las éticas compartidas. La tutela de la autonomía en el primer sentido atañe a la moral individual. Esta distinción tiene valor analítico, pero en la práctica no puede ser absoluta. Podría no ser posible defender uno u otro de sus términos: en efecto, no todas las éticas compartidas son "lícitas" desde el punto de vista de la "justicia" (porque algunas la pondrían en peligro en caso de que ahogaran la raíz, la autonomía como facultad de agency). 
sino de condicionar que la vida está asociada a la garantía de corrección de las relaciones intersubjetivas. Si el Derecho coincide con la garantía de las relaciones "racionales" de justicia intersubjetiva, entonces no puede asumir el valor o el papel de un "simple medio".

En conclusión, la corrección de la tesis según la cual el rule of law constituye un "medio" depende obviamente de la definición dada al concepto. Es importante repetir que tal tesis no puede extenderse sin equívocos al Derecho moderno en el sentido propuesto por KANT; el Derecho, como he recordado, ya no tiene únicamente las propiedades técnicas de un instrumento, sino que también posee la propiedad racional de control de las condiciones de justicia entre los individuos; en el sentido kantiano, sin necesariamente adoptar alguna ética determinada.

De cualquier modo, requisitos como la generalidad, la abstracción, la publicidad, la igual consideración, son en sí mismos instrumentos técnicamente esenciales para una eficiente guía de la conducta; se prestan efectivamente a una pluralidad de objetivos, y más allá de servir a la autoridad del "príncipe", al mismo tiempo parecen deseables también por lo que se refiere "aparte populi", porque están, a su vez, entre las condiciones indispensables (necesarias mas no suficientes) para el respeto a la "dignidad" de los individuos ${ }^{54}$.

Así, ahora es posible identificar las posibles implicaciones de fondo que las diversas definiciones de rule of law pueden designar: i) como instrumento cuyos principios eminentemente funcionales conservan un valor "negativo" de (necesaria pero no suficiente) tutela de la dignidad (RAz); o ii) como conjunto de condiciones que sustentan el telar de la justicia intersubjetiva (base de cualquier visión del bien, KANT), el rule of law se presenta con mucha mayor claridad como el escenario en el cual "todo" debe ocurrir; a partir de lo cual se deben articular sus principios formales (principios "funcionales" o bien principios de justicia) en su relación con los social goals y con las posibles éticas compartidas. Como tales, además no es posible excluir a estas últimas, las que en muchas ocasiones pretenden ser desacreditadas, pero que en nuestras sociedades aspiran a ser colocadas dentro de un "equilibrio" que justamente, al final, el Derecho tendría que adoptar, permitir y tutelar.

De esta manera, los principios formales del rule of law y aquellos sustantivos que pueden entrar en conflicto con los primeros (como el principio de solidaridad, el principio de autonomía individual, etc.) tienen un peso que debe ser balanceado, "ponderado", puesto en equilibrio recíproco.

La imposibilidad de traducir el rule of law de medio a fin, o bien de estructurar la convivencia como objetivo último de justicia (se trataría de una indebida anteposición del instrumento a cuyos objetivos debería servir, ya sea bien a la justicia o a la ética), significa, en ambos casos, que la fuerza de sus principios formales no es absoluta. Además nos provee de premisas suficientes para rechazar tesis como aquella sustentada por SCALIA, orientada en realidad a privilegiar la certeza del Derecho, capaz de transformarse en una clausura puramente "textualista" y formalista del Derecho.

54 Sin embargo, esto, como lo he explicado, en RAZ aparece sólo como una consecuencia del perfil de la autoridad práctica, de guía de las conductas, que describiría la esencia del rule of law. 
Se podría llegar a bastantes más conclusiones: en primer lugar, debido a que la estructura del Derecho está basada en los requisitos "formales" del rule of law, los mismos no pueden ser puestos en peligro; en segundo lugar, ello no implica que las virtudes del rule of law deban ser transformadas en requisitos inmunes a un juicio de proporcionalidad con tal de impedir el respeto a ciertos cánones concurrentes, como, por ejemplo, la garantía del "contenido esencial" (essential core) de los derechos (presentes explícitamente en el ordenamiento alemán o en la Constitución europea) ${ }^{55}$.

El equilibrio entre ambas exigencias no se puede mantener si no se tiene en cuenta que el ordenamiento tiene una estructura compleja formada por reglas y principios.

Por supuesto que esta tesis acerca de la coexistencia de reglas y principios ante todo parece repetir aquella expresada por DwORKIN; sin embargo, éste la orienta de modo unidireccional; como se ha dicho, el intérprete dworkiniano refiere los principios exclusivamente a los derechos morales de los individuos. Pero, como se ha señalado, entre los principios que pueden entrar autorizadamente en competencia también están los principios funcionales o de justicia del rule of law.

Esto es relevante, precisamente cuando abordamos el problema del abuso. Aquí los términos de la cuestión no dependen de un choque entre reglas y principios; choque que en DwORKIN estaría destinado fatalmente a la victoria de los segundos (rights) sobre las primeras (rules). Se trata, en su lugar, de una comparación entre principios, entre aquellos del rule of law que están concretados en forma de reglas y cualquier otro principio sustantivo competidor que proteja intereses colectivos o derechos individuales.

Cualquier desequilibrio injustificado producido en nombre del rule of law, se podría concluir, coincidiría con un abuso del rule of law.

\section{DEL RULE OF LAWAL ABUSO DEL PODER}

Diversos estudios, sobre todo en el área de la teoría general del Derecho, adoptan algunos elementos de asociación entre figuras como el abuso de derecho (subjetivo) y una figura específica del abuso de poder: la del uso desviado de los poderes públicos (desvío). La idea de conectar abuso y detournement de pouvoir ha sido sostenida sobre todo en el ámbito del institucionalismo jurídico francés ${ }^{56}$, no sin discusión y críticas de parte de muchos autores ${ }^{57}$. La doctrina administrativista europea se refiere con esta expresión a aquellos casos en los que el poder público es utilizado para algún objetivo diferente al cual ha sido instituido. Como ya he mencionado, también en el caso del desvío es necesario recurrir a principios. Ahora bien, como ATIENZA y RUIZ MANERO han señalado para interpretar si los fines típico-legales han sido "vulnerados”, «(...) es necesario recurrir a los principios que justifican tanto la propia regla que confiere el poder como las reglas regulativas que determinan su uso permitido» ${ }^{58}$.

\footnotetext{
55 Ley Fundamental alemana, art. 19/2; Constitución de la Unión Europea, art. II-112/1.

56 Se puede ver a Hauriou, M., 1898: Précis élémentaire de droit administratif, Paris, p. 190.

57 Por ejemplo, Giorgianni, 1963: p. 149.

58 Atienza y Ruiz Manero, 2004: pp. 98-99.
} 
Lo distintivo del abuso-desvío de poderes públicos es que se deben valorar las consecuencias, en términos fácticos, en particular si tales consecuencias constituyen un daño injustificado o un beneficio indebido; ambas situaciones excluidas por los principios que justifican en el ordenamiento la atribución del poder que ha sido usado. Un poder público, a diferencia del privado que es libre en la persecución de sus objetivos, está instituido para conseguir fines que materializan el interés público; más aún cuando está encaminado formalmente a perseguirlos ${ }^{59}$; sin embargo, en los hechos el ejercicio de esos poderes puede producir estados de cosas inaceptables ${ }^{60}$ al violar principios jurídicos (por ejemplo, establecer legítimamente prima facie un determinado número clausus en el acceso universitario podría tener el resultado de hecho, que bajo circunstancias concretas se hiciera imposible el acceso a una cierta categoría de sujetos asociada y definida por cierta religión; o al ordenar el tráfico se podría generar un estado que de hecho injustamente da ventajas a una empresa de transportes en perjuicio de otras ${ }^{61}$. Esta lógica también podría aplicarse en línea teórica al legislador, en caso de que en el ejercicio de la función legislativa termine por violar principios constitucionales, o al juez, por ejemplo en casos donde haga uso del poder de detención cautelar (custodia) sencillamente para condicionar al acusado «a asumir una determinada conducta procesal» ${ }^{62}$. Es significativo que el recurso a la idea misma de desvío de poder haya ocurrido a instancia del Consejo de Estado francés para intervenir sobre la discrecionalidad administrativa, en clara reacción al formalismo jurídico detrás del que se ocultaba.

Querría enmarcar esta visión de las cosas en una idea más general; en la legitimidad que tienen los poderes públicos para determinar la aplicación o el empleo de una regla. Si el rule of law es entendido bajo la postura del "poder de las reglas", el abuso del rule of law no depende meramente de la violación de las mismas; sin embargo, tampoco depende sencillamente del hecho de haber producido daños o perjuicios a derechos preexistentes. El problema se entiende mejor si se acepta que el ejercicio de los poderes públicos puede generar legítimamente tanto beneficios como daños. Como podría ser para un propietario la calificación de su solar como edificable o agrícola: en todo caso, esto no puede hacerse de forma arbitraria; esto es, violando los principios de no arbitrariedad, sensatez, eficiencia, economía, tal y como señala la jurisprudencia y la doctrina italiana u otros que podrían ser relevantes.

Esta circunstancia muestra que contrastar el empleo del poder público sobre la base de los derechos violados no resulta para nada una buena estrategia. En estas circunstancias, puesto que la vía del reclamo de los derechos resulta vana, ayudaría más a combatir el abuso de poder si lo analizamos en términos de desvío.

59 De otra manera se trataría de fines excluidos por las reglas que confieren poderes, esto es, de una violación de normas, de un ilícito típico, no atípico, no estaríamos en presencia del particular "abuso" que es el "desvío".

${ }^{60}$ El desvío reingresa en aquellos vicios de la acción pública que la doctrina administrativa considera violaciones de los límites internos de la discrecionalidad administrativa «que no están consagrados expresamente en normas legales»; en particular los juristas italianos creen que el desvío está presente cuando el interés no es definido como interés público o cuando «la causa del acto no resulta ser aquella típica del poder, para cuyo ejercicio ha sido emitida» (VIRGA, P., 1976: La tutela giurisdizionale nei confronti della pubblica amministrazione, 2. ${ }^{a}$ ed., Milano, pp. 264-265).

${ }_{61}$ Cfr. Atienza y Ruiz Manero, 2004: pp. 106 y ss.

62 Atienza y Ruiz Manero, 2004: p. 114. 
En este punto puede resultar útil el caso Plyler vs. Doe resuelto en 1982 por la Corte Suprema estadounidense. Sobre el mismo, Owen Fiss subraya que no habría tenido sentido, en contra de la medida legislativa (del Estado de Texas) que excluía de la enseñanza secundaria a los hijos de inmigrantes que habían accedido al país de forma ilegal, objetar que tal medida violaba la prohibición de discriminación y, por tanto, los derechos que se desprenden del principio de igualdad y de la Equal Protection Clause. Esto porque en línea de principio siempre es posible que los poderes públicos distingan o discriminen a través de medios legales; es suficiente que exista un reconocido y racional objetivo público para que el criterio discriminatorio opere. En el caso señalado, en contra del poder excluyente ejercido por el Estado de Texas, la Corte Suprema señaló que, más allá de los derechos que se desprenden del principio de no discriminación, otro argumento pudo y debió haber sido utilizado para censurar los efectos irracionales de la medida, efectos que violan el "anti-caste principle", que además también se desprende de la Equal Protection Clause. Dicho principio es aquel que prohíbe promover una sociedad de desiguales (unequals), de castas y de parias, en la que algunos sujetos quedan socialmente y económicamente en inferioridad y subordinación.

Las consecuencias son pues ilícitas, pero no sobre la base de un principio que tutela los derechos, sino de un principio diferente que tiene que ver con el interés público: el principio de no-subordinación, el cual protege a la sociedad americana como un «community of equals» ${ }^{63}$.

Por otro lado, que el ejercicio del poder pueda ser frenado por la lógica de los límites internos, aquellos que se refieren al abuso de poder en general, antes que por la violación de los derechos, parece bastante comprensible en el universo jurídico europeo.

En cierto sentido, si se piensa en determinados ordenamientos como el italiano (que junto al francés y al alemán mantienen continuidad en muchos aspectos) es como si en ellos estuviera inscrito con antelación, a priori, una diversidad de planos que hacen también hoy y lo han hecho por tradición que sea jurídicamente imposible una colisión entre derechos individuales y el ejercicio de los poderes legales lícitos prima facie (o sea conformes a las reglas, conformes al "rule of law as law of rules"). Entonces la imposibilidad de la colisión está presupuesta conceptualmente en la misma construcción del Estado administrativo y de la justicia (jurisdicción) administrativa de la Europa contemporánea continental. Por tanto, no es jurídicamente posible oponerse al poder público a través del arma de los derechos individuales. Esto porque la relación entre el poder público que se vale de una norma legal y la esfera de los derechos privados es una relación a menudo parecida a la concedida por EPICURO entre nosotros y la muerte: no hay razón para temerle, puesto que, mientras nosotros estamos, ella no está; y si ella está, nosotros no estamos más. Si el ejercicio de un poder refleja una regla legal que goza de una legitimidad prima facie, el derecho subjetivo, por ejemplo del propietario expropiado, se presenta "debilitado", es decir, transformado en un "interés" (en interés legítimo). Es significativo que el ciudadano que entra en con-

${ }^{63}$ FIss, O., 1999: A Community of Equals. The Constitutional Protection of New Americans, Boston: ed. J. Cohen, J. Rogers, p. 12. 
tacto con el ejercicio de los poderes institucionales del poder público y se cree perjudicado por un acto legal de la administración pública, no puede alegar contra este adversario dotado de "supremacía" ${ }^{64}$ el propio derecho (por ejemplo el de propiedad), tampoco en un juicio puede recurrir ante el juez (administrativo, no ordinario) alegando un interés, cualificado o justificado, en controlar que la acción de la administración haya sido emitida en el marco del respeto a la legalidad, sin exceso de poder, sin falta de competencia. Obviamente, el problema no se vería en estos términos si el poder público emitiera actuaciones radicalmente equivocadas, como podría ocurrir si lo hiciera en ausencia de una regla de competencia del poder que dice ejercer; en cuyo caso no dispondría de ninguna supremacía, ni de ninguna protección particular respecto de aquellas que tiene cualquier ciudadano privado.

Esta atmósfera propia de la tradición estatal europea hace más interesante la teorización de la lógica del abuso de poder, en el sentido señalado según el cual el desvío es deducible de un control que tiene su origen en los principios de justificación, y no sólo en la conformidad con la "regla" que lo confiere y lo autoriza.

Desde la perspectiva del abuso, se tiene la sensación de que la figura "atípica" del desvío es atribuible a la idea de un abuso del rule of law, en el sentido de abuso del principio de legalidad de la acción. Esto consiste: $a$ ) en que el poder efectivo radica en el mando del órgano que lo ejercita y en el respeto a los poderes atribuidos por la ley, y, además, b) en la incapacidad de las consecuencias de la acción de resistir la prueba de los principios que gobiernan el ejercicio de ese poder. Con esto, lo subrayo, no estamos frente a un conflicto entre derechos y el rule of law. El abuso del rule of law se puede distinguir del simple abuse of rights, en el sentido, esta vez, de la lesión de los derechos.

\section{UN EXPERIMENTO JURÍDICO. EL ABUSO DEL RULE OF LAW EN GUANTANAMO BAY}

Para concluir, bajo esta lógica es posible además reconstruir problemas diversos acerca del control judicial del ejercicio de poderes públicos. En el caso Padilla vs. Rumsfeld ${ }^{65}$, la Corte Suprema estadounidense negó la admisión del "babeas corpus petition" solicitado por el recurrente Padilla porque la petición iba dirigida a una Corte Federal de Nueva York y no a la de South Carolina, Estado en el que, dos días después de su detención y una vez calificado como "enemy combatant", Padilla fue trasladado; la Corte sostuvo que el "babeas statute" requiere, en términos generales, que

\footnotetext{
${ }^{64}$ El concepto de "supremacía”, al cual siempre se ha opuesto la cultura jurídica anglosajona, está presente ante todo en el iuspublicistia alemán Otto MAYER, 1895: Deutsches Verwaltungsrecht, I, Berlín, quien distingue la personalidad del Estado de la persona según el Derecho civil (MAYER, 1895: p. 49), define la supremacía a partir de la desigualdad entre el Estado y los sujetos, por consiguiente derivado del hecho de que el Estado cuenta con poder público (MAYER, 1895: p. 67). La cultura jurídica anglosajona se mueve en un concepto opuesto. Si bien la incompatibilidad con la creación de tribunales administrativos adecuados tenga que entenderse como superada, no obstante, la definición conceptual de las relaciones entre Estado, Administración y ciudadanos es distinta ( $c f r$. DiCEY, 1885: pp. 193 y ss. Sobre DiCEY en general, cfr. CASSESE, S., 1990: «Albert Venn Dicey e il diritto amministrativo», Quaderni fiorentini, 19, pp. 19 y ss.).

65542 US 426 (2004).
} 
las peticiones contra las medidas de detención sean propuestas en el distrito más cercano a aquel en el que ocurre la detención. Hacerlo de otra manera permitiría un "forum shopping" a favor del detenido, o sea, la libre elección según su propio interés de la Corte donde haya de ser juzgado. Cuando la competencia del foro debe considerarse inderogable. No obstante esta postura, las palabras redactadas por el juez Stevens en su voto particular señalan una serie de abusos: el primero cometido por las autoridades militares; que parecieran entender el poder de trasladar al preso como si consistiera en "un derecho de procesar" a las personas arrestadas en cualquier sitio elegido por el poder militar; el segundo es igualmente visible en las consideraciones ulteriores de Stevens:

Si el imputado tiene o no derecho a una liberación inmediata es una pregunta a la que juristas razonables pudieran dar soluciones diferentes. En todo caso, sólo hay una respuesta posible a la pregunta de si tiene derecho a ser puesto en conocimiento sobre las razones de su detención ${ }^{66}$.

Como se aprecia, lo que está en juego son las relaciones entre el poder ejecutivo y el rule of law. Los límites internos de los poderes del ejecutivo tienen que encontrarse, en este caso, en la relación entre el ejecutivo y el judicial, en el due process ${ }^{67}$, en el rule of law. Esos límites no pueden ser frustrados por el servil respeto a la fórmula literal de una regla de procedimiento; lo que se debe tratar de establecer es si los actos cumplidos por la administración militar son expresión de un empleo que llamaríamos "desviado" a la luz de los principios subyacentes a la norma.

En esta parte, el abuso del rule of law puede ser deducido precisamente de las palabras de la dissenting opinion de Stevens, según la cual el que la detención de ciudadanos subversivos tales como Padilla o la detención de soldados enemigos esté dirigida a alejarlos del campo de batalla, podría estar justificada por el intento de impedir que se lancen, o se transformen en misiles de destrucción. En cualquier caso, no puede justificarse en el mero interés de usar procedimientos ilegales para extraerles información ${ }^{68}$.

Una detención sin comunicación alguna, dilatada por varios meses, «constituye precisamente uno de tales procedimientos» ${ }^{69}$. Si después la información que se indaga por esos medios es menos confiable que aquella adquirida por medios más extremos como la tortura no es una cuestión relevante aquí. En definitiva, si esta nación quiere

${ }^{66}$ Ibid., p. 464.

${ }^{67}$ Como es conocido, se trata de la Quinta enmienda (1791) de la Constitución federal estadounidense que prevé que «nadie pueda ser privado de vida, de la libertad o de la propiedad sin el due process of law». Inicialmente el sentido de esta previsión fue interpretada por la Corte Suprema como referida a los «procedimientos tradicionales del common law», y sucesivamente como referida a procedimientos «fundamentalmente justos» [fundamentally fair (cfr. Powell vs. Alabama, 287 US 45, 1932), en donde se sostuvo que los acusados indigentes tienen derecho a un abogado por cuenta del Estado, aunque no lo previera el common law].

${ }^{68}$ Padilla vs. Rumsfeld, op. cit., p. 465.

${ }^{69}$ Con mayor razón si se toma en cuenta aquello que el propio Stevens refiere: los poderes militares que han puesto en custodia al detenido «han sido significativamente candidos a propósito del motivo de la detención del imputado» y han declarado: «nuestro interés en el caso específico no es la aplicación de la ley, no es el castigo para hacer de él ante el estado un terrorista o un colaborador de los terroristas. Nuestro interés en ese momento es buscar y encontrar cualquier cosa que sepa, y así seguramente lograr detener otros actos terroristas» (233 F. Supp. 2d 564, 573-574 SDNY 2002) [tomado de News Briefing, Dept. of Defense (June 12, 2002), 2002 WL 22026773]. 
ser fiel a los ideales simbolizados por su bandera, no debe recurrir a los instrumentos de los tiranos, aunque tenga que resistir un ataque que proviene de fuerzas tiránicas ${ }^{70}$.

Como es evidente, esta argumentación no se apoya en la prioridad de los derechos humanos; por el contrario, se apoya en lo inaceptable de las finalidades reales del poder una vez confrontado con los principios relevantes que lo regulan. Por tanto, el argumento se muestra diferente porque hace referencia a la idea de abuso del poder o de derecho, antes que a la tesis de la violación o la denegación de derechos humanos.

Se trata de un argumento diferente de aquel que, por ejemplo, puede leerse en las palabras de Ronald DwORKIN. Autor que sacude la convicción de la "Administración Bush", según la cual el Derecho vigente permite detener indefinidamente a algunos prisioneros calificados como "unlawful combatants", sin acusación o proceso y someterlos a interrogatorios sin las garantías mínimas favorables de las que gozan los prisioneros de guerra: «que todo esto sea o no permitido por la Carta del Derecho internacional es irrelevante, la decencia y el respeto de los derechos humanos exigirían que la administración los deje aparte y elija entre perseguir a sus prisioneros como criminales, con las garantías ordinarias del proceso penal, o tratarlos como prisioneros de guerra». Esta elección en efecto pondría punto final a las formas de humillación como la privación física y psicológica a la que los presos son sometidos; de hecho, «la actual política seguida por el gobierno muestra un inaceptable desprecio por los derechos y la dignidad de sus víctimas» ${ }^{71}$.

Estas consideraciones siguen un itinerario que no pasa por el abuso de poder, pero sí por la prioridad de los derechos humanos; una vía que, sin embargo, en la práctica en algunos casos se puede revelar más difícil de recorrer.

Para continuar sobre este punto, es igualmente significativo el bien conocido caso de la detención de personas por diversos motivos en la base de Guantánamo; personas que también solicitaron conocer sus acusaciones y las razones del encarcelamiento indefinido. La administración Bush ha respondido a partir de una línea de defensa basada en reglas, antes que en su justificación.

Esmeradamente ha evitado determinar la definición de qué derechos deben garantizar las autoridades militares a la diversidad de sujetos detenidos, tanto a combatientes regulares de un Estado enemigo, como a combatientes irregulares y terroristas aislados, personas simplemente sospechosas o ciudadanos de un país amigo, y así sucesivamente. Los Estados Unidos quizás habrían podido defender el mérito de su propio proceder, si hubieran sostenido que habían respetado el due process o a la Convención de Ginebra, incluso no aceptando por completo todas las solicitudes de defensa y contradictorio por razones de seguridad nacional, dadas las circunstancias dramáticas de la guerra contra el terrorismo. Sin embargo, el gobierno ha elegido sencillamente negar que los detenidos puedan recibir cualquier tipo de protección constitucional, suponiendo que no habría instrumentos para extender el habeas corpus más

${ }^{70}$ Padilla vs. Rumsfeld, op. cit., p. 465.

${ }^{71}$ DworkIn, R., 2004: «What the Court Really Said», The New York Review of Books, vol. 51, n. ${ }^{\circ} 13,12$ de agosto. DwORKIN retoma aquí su artículo anterior, 2003: «Terror and the Attack on Civil Liberties», The New York Review, 6 de noviembre. 
allá de las jurisdicciones "naturales" de las Cortes federales: desafortunadamente los prisioneros no se encuentran en los Estados Unidos, bajo su "soberanía", sino en Cuba.

Este argumento "formal" es una clásica referencia a los límites establecidos por las reglas del rule of law, pero, como tal, el aparente respeto a una regla legislativa es utilizado para ocultar un exceso a los límites internos en principio asignados al tipo de poder ejercitado en este caso.

Aunque resulta patente la violación de los derechos humanos de los detenidos, la cuestión aparece fuera de focus, del plano sobre el que se desarrolla la confrontación jurídica. Más allá de cualquier cosa que se piense sobre los derechos humanos y el habeas corpus, el problema es que el gobierno ha podido proveerse de un "lugar" fuera del alcance del poder deontológico de los derechos civiles y de los derechos humanos, un lugar donde resulta procesalmente inadmisible y no disponible cualquier jurisdicción, de forma que lo que se manifiesta no es el Derecho, sino sólo el poder.

Por esta razón, mientras que argumentar a través de la lente de los derechos humanos puede resultar estratégicamente inútil, parece relativamente más conveniente cuestionar la legalidad del poder sobre la base de sus mismos principios, y así acceder al problema del abuso del rule of law.

La Corte Suprema en el caso Rasul vs. Bush ${ }^{72}$ ha rechazado los argumentos de la Administración americana, concediendo el babeas corpus y tocando sustantivamente la "raíz", los fines y el sentido del poder público. Ante todo, según la Corte, el Congreso ha otorgado a las Cortes federales del distrito, «dentro de sus correspondientes jurisdicciones», la autoridad, el poder, la competencia de recibir peticiones de «babeas corpus de cualquiera persona que reclame estar custodiada "en violación de la Constitución, de las leyes o de los tratados de los Estados Unidos" ${ }^{73}$. La razón histórica y la justificación de principio de tal autoridad es obviamente el control y la limitación de los preponderantes y como tales preocupantes poderes del ejecutivo ${ }^{74}$. Por otro lado, el habeas corpus pertenece al common law antes que a las leyes emanadas del Congreso para regularlo.

Finalmente, desde el punto de vista de la interpretación de la ley, la Corte retoma un precedente a partir del cual deduce que el ámbito de jurisdicción debe de ser entendido como referido al lugar de pertenencia y «custodia» no aquel a donde deben ser llevados los detenidos ${ }^{75}$.

72542 US 466 (2004).

73 La Corte cita aquí 28 USC. $\$ 2241($ a), (c)(3).

${ }^{74}$ La Corte retoma estas justificaciones de casos anteriores: «[a]t its historical core, the writ of habeas corpus has served as a means of reviewing the legality of Executive detention, and it is in that context that its protections have been strongest», INS vs. St. Cyr, 533 U. S. 289, 301 (2001). También ver: Brown vs. Allen, 344 U. S. 443, 533 (1953) (JACKSON, J., concurring in result) («The historic purpose of the writ has been to relieve detention by executive authorities without judicial trial»).

75 Aquí la Corte hace referencia a la sentencia anterior Braden vs. 30th Judicial Circuit Court of Ky., 410 US 484 (1973). Se lee, en efecto: «this Court held, contrary to Abrens, that the prisoner's presence within the territorial jurisdiction of the district court is not "an invariable prerequisite" to the exercise of district court jurisdiction under the federal habeas statute. Rather, because "the writ of habeas corpus does not act upon the prisoner who seeks relief, but upon the person who holds him in what is alleged to be unlawful custody", a district court acts "within [its] respective jurisdiction" within the meaning of $\$ 2241$ as long as "the custodian can be reached by service of process”, 410 U. S., pp. 494-495». 
Más allá de la letra del precedente, el recurso al mismo que utiliza la Corte depende de la opción por el principio que justifica la autoridad de las Cortes, que hace posible controlar la fuerza del poder ejecutivo; no aquel que lleva a limitar o excluir la jurisdicción para proveer al ejecutivo de una zona franca. Bajo esta óptica, aquella disposición legislativa «within their jurisdictions» debe ser entendida ante todo en el interés y con respecto a la posición del detenido. Es por esta razón que el habeas corpus también debe ser garantizado en un territorio sobre el que los Estados Unidos ejercen una plena y exclusiva jurisdicción, mas no una «ultimate sovereignty».

Por contraste, igualmente significativa y reveladora es la dissenting opinion del juez Scalia, quien sostiene el deber de mantenerse firme al texto de la previsión del $₫ 2241$ de la ley federal al igual que desestima el fundamento de las posiciones mayoritarias asumidas por los jueces de la Corte; sobre este particular aspecto:

Por costumbre, hemos tenido en cuenta los intereses de los que se han sometido a nuestra jurisdicción. Hoy la Corte hace saltar una trampa del ejecutivo al someter a la supervisión de las Cortes Federales a Guantanamo Bay, aunque hasta la fecha nunca antes se hubiera entendido que estuviera dentro de su jurisdicción; con ello tal lugar ha sido considerado un lugar donde es realmente insensato haber confinado a extranjeros detenidos en tiempo de guerra [and thus making it a foolish place to have housed alien wartime detainees $]^{76}$.

Así, según Scalia, abandonando la anterior línea interpretativa ya consolidada, la Corte «extiende el ámbito de aplicación de la ley sobre el habeas corpus a los cuatro rincones de la tierra» ${ }^{77}$.

El punto que defiende es que Guantánamo debió haber quedado como aquel en el que la civilización jurídica está en suspenso, por cuanto que eso es funcional a los intereses de los Estados Unidos. Pero creo que esto es justamente un abuso del rule of law, más todavía que una violación de los derechos humanos de los detenidos. Y ello en el sentido del ilícito que representa "construir" un lugar en el que el poder del ejecutivo es sustraído mágicamente a la jurisdicción de cualquier Tribunal, civil o militar. Esta ilicitud interna es el presupuesto para cumplir cualquier acto, incluso violaciones a los derechos humanos.

Según DwOrKin, el sentido de los pronunciamientos de la Corte es que «la Constitución no permite al Estado encarcelar indefinidamente bajo sospechas a combatientes enemigos o terroristas» sin acusarlos de algún crimen, y sin concederles la tradicional protección del Derecho penal, «a menos que sean tratados efectivamente como prisioneros de guerra. En cuyo caso gozarían de los beneficios y de las tutelas del Derecho internacional, incluida la Convención de Ginebra» ${ }^{78}$. Sin embargo, con esta respuesta DwORKIN sigue un camino diferente a aquel que he expuesto; esto es,

${ }^{76}$ Rasul vs. Bush, op. cit., pp. 497-498.

${ }_{77}$ Ibid. También se lee en una ulterior parte del dissent de Scalia: «The reality is this: Today's opinion, and today's opinion alone, overrules Eisentrager; today's opinion, and today's opinion alone, extends the habeas statute, for the first time, to aliens held beyond the sovereign territory of the United States and beyond the territorial jurisdiction of its courts. No reasons are given for this result; no acknowledgment of its consequences made. By spurious reliance on Braden the Court evades explaining why stare decisis can be disregarded, and why Eisentrager was wrong», ibid., p. 497.

${ }^{78}$ DWORKIN, 2004: p. 1. 
el referido al abuso del rule of law ${ }^{79}$. Y su argumento lo posiciona en un plano que no responde y además escapa a la cuestión planteada por Scalia.

$\mathrm{El}$ argumento "consecuencialista" aducido en el dissenting de Scalia es por el contrario que se ha defraudado la confianza de la administración americana; podríamos decir que se ha traicionado la virtud del rule of law, la certeza del Derecho y, por tanto, el principio de tutela judicial por cuanto que la Administración había confinado a los detenidos en Guantánamo con la certera convicción de hacerlo libre de cualquier "interferencia".

Uno no puede evitar sentirse golpeado por esta sorprendente crítica de las "consecuencias". Cándidamente, se da por descontado y legítimo que las autoridades militares asumieran poder sustraer de la ley a los detenidos, más aún, que tuvieran la certeza de haberlo hecho. A la espontaneidad con que es expuesta esta presuposición se puede replicar adecuadamente cuestionando justamente la legitimidad de la presuposición y su fundamento jurídico: ¿merece ser protegida la certeza de estar (o que el propio poder, gracias a la extraterritorialidad de Guantanamo, esté) legibus solutus?, ¿o configura un interés indigno que hace abusivo, descarriado y por tanto ilícito el uso del poder?

El indigno interés de sustraer a los prisioneros de la ley también revela que el poder ejercido (y la interpretación de Scalia) constituyen cuando menos un verdadero "desvío". Finalmente, las propias "consecuencias" del ejercicio del poder de detención en Guantánamo contrastan con principios fundamentales como el del control entre poderes (en este caso del control judicial sobre el ejecutivo).

Por otro lado, un aspecto diferente y opuesto merece ser mencionado: un presupuesto que a menudo explícitamente ocupa el centro de la discusión es el "principio" de la seguridad nacional, un principio sustancial, el verdadero convidado de piedra; este principio es asumido sin moderación en especial en la búsqueda de los medios adecuados y sin ningún balance con otros principios.

Una última característica que se deja entrever en tal hecho es que este desvío, incluso apelando a las formas del rule of law, se aprovecha de su carga emotiva, antes que de un vínculo pragmático ofrecido por la apelación a la seguridad, hasta vaciar de contenido la coherencia de los requisitos mínimos del rule of law. Esto sin considerar no sólo el riesgo simbólico, sino los peligros de poner entre paréntesis determinadas garantías primarias. El riesgo está en declarar un "estado de excepción" incluso cuando se haga en la tierra de nadie de Guantánamo; éste se presenta como un momento paralelo que convive con el estado jurídico pero que en última instancia puede desatarse de los lazos de la civilización jurídica y entregarse, por decirlo con una expresión de Carl SchmitT, a la tiranía de los valores.

(Trad. de Jesús Ibarra)

${ }^{79} \mathrm{El}$ juez Kennedy ha sostenido (concurring en Rasul) que aunque el habeas corpus y el due process no pueden ser garantizados del mismo modo para todas las circunstancias, una tutela mínima, compatible con el interés militar, debe ser prestada a todos los prisioneros incluso aquellos que no son ciudadanos de una nación en guerra (Rasul vs. Bush, op. cit., pp. 487-488). 